\section{miR-122, IL28B genotype and the response to interferon in chronic hepatitis $C$ virus infection}

\author{
Jae II Shin and Michael Eisenhut
}

In a recent article ( 25 years of interferonbased treatment of chronic hepatitis C: an epoch coming to an end. Nature Rev. Immunol. 13, 535-542 (2013)) $)^{1}$, Markus Heim reviewed the 25-year history of therapies for hepatitis $\mathrm{C}$ virus (HCV) infection and introduced some new pharmaceutical agents that target cellular proteins and the microRNA miR-122. The author also described an association between a polymorphism in interleukin-28B (IL28B; also known as IFNL3) and the response to interferon- $\alpha$ (IFN $\alpha$ ) treatment, but he did not review the molecular mechanisms that link genetic variation in the IL28B gene locus to the response to IFNa ${ }^{1}$. We would like to highlight a possible link between miR-122, the IL28B gene polymorphism and the response to IFNa treatment.

Janssen et al. ${ }^{2}$ recently reported a Phase IIa clinical study of miR-122-targeted therapy (miravirsen), which showed that the use of miravirsen in patients with chronic $\mathrm{HCV}$ genotype 1 infection leads to a prolonged dose-dependent reduction in $\mathrm{HCV}$ RNA levels and no signs of viral resistance. miR-122 is a highly abundant microRNA that is expressed in the liver and is essential for the stability and propagation of $\mathrm{HCV}$ $\mathrm{RNA}^{3}$. Recently, a report has shown that pretreatment levels of miR-122 are predictive of the response to IFN and that miR-122 levels might be related to the IL28B genotype ${ }^{4}$. Su et al. ${ }^{4}$ reported that serum levels of
miR-122 can be used as a surrogate marker of hepatic levels of miR-122 and that serum levels of miR-122 positively correlated with hepatic necroinflammation. Patients who showed a complete early and sustained response to treatment had significantly higher serum levels of miR-122 before treatment compared with patients who had no response; in particular, a strong response to treatment was shown by patients who were infected with HCV genotype 2 and had the IL28B rs8099917 TT genotype. Su et al. ${ }^{4}$ also showed that patients with the IL28B TT genotype had significantly better treatment responses and higher serum levels of miR-122 before treatment compared with those with the IL28B GT or GG genotypes ${ }^{4}$.

Therefore, the IL28B genotype-dependent variation in levels of miR-122 in serum could be one of the molecular mechanisms that links genotype to the response to IFNa ${ }^{5}$. This might be through a recently discovered mechanism by which IFNa-induced cytosolic 5' nucleotidase 3 (NT5C3) mRNA reduces miR-122 levels by sequestration, a process that is reversible by transduction with small interfering RNA that targets NT5C3. This mechanism links genotypes associated with an activated endogenous IFN system to a poor response to IFNa treatment ${ }^{6}$. Furthermore, the IL28B TT genotype is associated with the upregulation of expression of the IFNa receptor $\alpha$-chain, and it is possible that the increased action of endogenous IFNa might also enhance the degradation of the anti-HCV microRNA let-7b through the same NT5C3 mRNA-dependent mechanism. This reduction in let- $7 \mathrm{~b}$ levels could compromise the action of exogenous IFNa, which is known to act synergistically with let- $7 b^{7}$. Therefore, in this context, it is possible that miR-122 levels are just a correlate of let-7b levels and that the regulation of let $7 b$, and not miR-122, determines the response to exogenous IFNa. Because miR-122 acts as a tumour suppressor for hepatocellular carcinoma ${ }^{8}$, attention needs to be paid to the long-term outcome of treatment with suppressors of miR-122.

Jae II Shin is at the Department of Pediatrics, Yonsei University College of Medicine, 120-752, CPO Box 8044, Seoul, Korea

Michael Eisenhut is at the Department of Pediatrics, Luton and Dunstable University Hospital NHS Foundation Trust, Lewsey Road, Luton, LU4 ODZ, UK.

Correspondence to M.E. e-mail:michael eisenhut@yahoo.com

1. Heim, M. H. 25 years of interferon-based treatment of chronic hepatitis C: an epoch coming to an end. Nature Rev. Immunol. 13, 535-542 (2013).

2. Janssen, H. L. et al. Treatment of HCV infection by targeting microRNA. N. Engl. J. Med. 368, 1685-1694 (2013).

3. Henke, J. I. et al. MicroRNA-122 stimulates translation of hepatitis C virus RNA. EMBO. J. 27, 3300-3310 (2008).

4. Su, T. H. et al. Serum microRNA-122 level correlates with virologic responses to pegylated interferon therapy in chronic hepatitis C. Proc. Natl Acad. Sci. USA 110, 7844-7849 (2013).

5. Hayesl, C. N., Imamura, M., Aikata, H. \& Chayama, K. Genetics of IL28B and HCV-response to infection and treatment. Nature Rev. Gastroenterol. Hepatol. 9 , 406-417 (2012)

6. Hao, J. et al. Inhibition of alpha interferon (IFN- $\alpha$ )induced microRNA-122 negatively affects the antihepatitis B virus efficiency of IFN- $\alpha$. J. Virol. 87 , 137-147 (2013)

7. Cheng, J. C. et al. Let-7b is a novel regulator of hepatitis C virus replication. Cell. Mol. Life Sci. 69, 2621-2633 (2012).

8. Tsai, W. C. et al. MicroRNA-122, a tumor suppressor microRNA that regulates intrahepatic metastasis of hepatocellular carcinoma. Hepatology 49. 1571-1582 (2009).

Competing interests statement The authors declare no competing interests. 